Applied Physiology, Nutrition, and Metabolism

Canadian

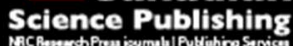
Physiologie appliquée, nutrition et métabolisme

\title{
Acute glutamine ingestion modulates lymphocytic responses to exhaustive exercise in the heat
}

\begin{tabular}{|r|l|}
\hline Journal: & Applied Physiology, Nutrition, and Metabolism \\
\hline Manuscript ID & apnm-2017-0212.R3 \\
\hline Manuscript Type: & Article \\
\hline Date Submitted by the Author: & $13-$ Sep-2017 \\
\hline Complete List of Authors: & $\begin{array}{l}\text { Zheng, Chen; Beijing Sport University, Department of Exercise Physiology ; } \\
\text { The Chinese University of Hong Kong, Department of Sport Science and } \\
\text { Physical Education } \\
\text { Chen, Xiang-Ke; Beijing Sport University, Department of Exercise } \\
\text { Physiology; The University of Hong Kong, Department of Medicine } \\
\text { Zhou, Yue; Beijing Sport University, Department of Exercise Physiology }\end{array}$ \\
\hline $\begin{array}{r}\text { Is the invited manuscript for } \\
\text { consideration in a Special } \\
\text { Issue? : }\end{array}$ & \\
\hline Keyword: & $\begin{array}{l}\text { glutamine, acute ingestion, exercise in the heat, immune function, } \\
\text { lymphocytosis }\end{array}$ \\
\hline \multicolumn{2}{|c}{} \\
\hline
\end{tabular}


Acute glutamine ingestion modulates lymphocytic responses to exhaustive exercise in the heat

Chen Zheng ${ }^{1,2} *$, Xiang-Ke Chen ${ }^{1,3} *$, Yue Zhou ${ }^{1}$

${ }^{1}$ Department of Exercise Physiology, Beijing Sport University, Beijing, China

${ }^{2}$ Department of Sport Science and Physical Education, The Chinese University of Hong Kong, Hong Kong, China

${ }^{3}$ Department of Medicine, The University of Hong Kong, Hong Kong, China

* These authors contributed equally to this work

\section{Corresponding author}

Prof. Yue Zhou,

Department of Exercise Physiology,

Beijing Sport University,

Xinxi Road, Haidian District,

Beijing, China

Email: zhouybsu@hotmail.com

Tel: +86 136-9359-3116

\section{Co-authors}

Chen Zheng (zhengchen@link.cuhk.edu.hk)

Xiang-Ke Chen (xkchen@hku.hk) 


\section{Abstract}

The purpose of this study was to determine if acute intake of glutamine modulates homeostatic, hematologic, immune, and inflammatory responses to exhaustive exercise in the heat. Thirteen healthy untrained young men participated in this randomized, double-blind, placebo-controlled, crossover study. They served as their own control and completed two trials of treadmill exercise at $40 \% \mathrm{VO}_{2 \max }$ to exhaustion in a hot environment $\left(38.0 \pm 1.0{ }^{\circ} \mathrm{C}, 60.0 \pm 5.0 \%\right.$ relative humidity, and 20.8\% oxygen) following placebo (PLA) and glutamine (GLN) consumption. Heart rate, gastrointestinal temperature, forehead temperature, the rating of perceived exertion, and body weight were measured. Blood samples were collected pre- and post-exercise. After exhaustive exercise in the heat (PLA vs. GLN: $42.0 \pm 9.5$ vs. $39.6 \pm 7.8 \mathrm{~min}, \mathrm{p}>0.05$ ), significant changes in homeostatic, hematologic, and immune parameters (elevated natural killer [NK] cells and neutrophils, and reduced CD4+/CD8+ ratio and CD19+ lymphocytes) were found in the control group due to the time effect $(\mathrm{p}<0.05)$. Moreover, a condition $\times$ time interaction effect was observed for the absolute count of $\mathrm{CD} 3+(\mathrm{F}=4.26, \mathrm{p}<0.05)$ and $\mathrm{CD} 3+\mathrm{CD} 8+\mathrm{T}$ lymphocytes $(\mathrm{F}=4.27, \mathrm{p}<0.05)$, which were elevated following acute glutamine intervention. While a potential interaction effect was also observed for the absolute count of $\mathrm{CD} 3+\mathrm{CD} 4+\mathrm{T}$ lymphocytes $(\mathrm{F}=3.21, \mathrm{p}=0.08)$, no condition or interaction effects were found for any other outcome measures. The results of this study suggest that acute glutamine ingestion evokes CD3+ and CD3+CD8+ T lymphocytosis but does not modulate neutrophil and NK cell leukocytosis and immune disturbances after exhaustive exercise in the heat.

Keywords: glutamine; acute ingestion; exercise in the heat; immune function; lymphocytosis 


\section{Introduction}

Leukocyte trafficking is an essential mechanism involved in maintaining immune homeostasis, whereby the 'soldiers' of immune system rapidly migrate to the sites of immune activation (Sprent \& Tough, 1994; Butcher et al., 1999). Accordingly, the effective trafficking of leukocytes, which is very sensitive to stress, may mediate protective effects in patients suffering from multiple conditions such as infection, trauma, or localized cancer (Viswanathan \& Dhabhar, 2005). These protective effects primarily cover the immune surveillance and subsequent elimination of virally infected, tumor, damaged, and senescent cells (Simpson et al., 2010 \& 2011; Pedersen et al., 2016). Acute exercise and fever-range thermal stress-induced mobilization of leukocytes into the bloodstream, referred to as leukocytosis, are the well-documented stress-induced enhancements of leukocyte trafficking (Chen et al., 2006; Krüger et al., 2008). Conversely, vigorous exercise training and extreme hyperthermia suppress the leukocyte trafficking and functioning (Ahlers et al., 2005; Witard et al., 2012). Additionally, amplified mobilization of leukocytes has been identified during exhaustive exercise in the heat compared to that in temperate environments, while exercisers may suffer a higher risk of upper respiratory tract infection and heat-related illness at the same time consequently leading to impaired athletic performances (Walsh \& Whitham, 2006). It is important to note that acute exercise in the heat is a potential immunotherapy for boosting leukocyte trafficking, but it also poses formidable challenges in the immune homeostasis resulting in health disturbance.

Glutamine, which is classified as a non-essential amino acid, is crucial for the maintenance of proper immune function, particularly under stressful conditions such as exercise, trauma, and hyperthermia (Walsh et al., 1998). It was originally thought that deficiency of plasma glutamine was considered responsible for these strains-induced transient disturbances in immune system 
(Rohde et al., 1997; Boelens et al., 2004; Pollheimer et al., 2005), but subsequent studies have shown that reversing glutamine insufficiency is an immunomodulatory strategy for hyperthermia and other clinical illnesses-related but not the exercise-induced immunosuppression (Hiscock \& Pedersen, 2002; Singleton and Wischmeyer, 2006; Gleeson, 2008; Wernerman, 2008). Nevertheless, strong evidence from marathon athletes indicates that the reports of infection are reduced following interventions of glutamine (Castell et al., 1996). Recently, several studies have reported that a relative excess glutamine in plasma following glutamine consumption alleviated immune dysregulation in exercisers, even without glutamine deficiency, possibly through modulating inflammatory cytokines, heat shock proteins (Hsps), and nasal immunoglobulin-A (IgA) (Krieger et al., 2004; Caris et al., 2014; Zuhl et al., 2014). In addition, alanyl-glutamine supplementation is considered beneficial for effector $\mathrm{T}$ cell functioning and leukocyte trafficking including leukocytes migration or adhesion (Bunpo et al., 2008). Therefore, glutamine ingestion remains as a potential modulator for immune responses to various types of stress, although the mechanism requires further investigation.

In the past several decades, the concern of side effects due to chronic or high-dose glutamine feeding has emerged, leading to the recommendation that glutamine be consumed in moderation to avoid ill effects in healthy adults (Gleeson, 2008; Holecek, 2012). In the majority of previous studies, however, chronic feeding of glutamine was extensively utilized, whereas only very few studies have been conducted with acute intake of glutamine (Rezende Freitas et al., 2015). These acute-ingestion studies have shown that acute glutamine ingestion, which is similar to the chronic supplementation, can also protect peripheral leukocytes from exercise stress through elevated Hsp70 expression (Zuhl et al., 2015). However, there are few studies regarding the impact of acute doses of glutamine, which are much safer than chronic ingestion, on exercise or hyperthermia- 
induced immune responses and disturbances. Additionally, it is conceivable that acute ingestion of glutamine may have different effects than chronic ingestion, particularly regarding immune responses to acute stress. Therefore, the purpose of this study was to investigate the impacts of acute glutamine ingestion on immune, homeostatic, hematologic, and inflammatory responses to long-term treadmill exercise under heat stress.

\section{Materials and Methods}

\section{Participants}

Thirteen healthy untrained young males (age, $20.2 \pm 1.1$ years; height, $177.8 \pm 3.9 \mathrm{~cm}$; mass, $71.3 \pm$ $7.3 \mathrm{~kg}$; maximum oxygen uptake $\left[\mathrm{VO}_{2 \max }\right], 55.9 \pm 3.9 \mathrm{ml} \cdot \mathrm{kg}^{-1} \cdot \mathrm{min}^{-1}$ ) volunteered to take part in the study. None of the participants reported any medical conditions, taking supplements, or living in a frigid or torrid zone. All procedures were explained to the participants before data collection. This study was approved by the Institutional Review Board at Beijing Sport University, and written informed consent was obtained from all participants.

\section{Experimental design}

Using a randomized, double-blind, placebo-controlled, crossover research design, each subject served as his own control and participated in $\mathrm{VO}_{2 \max }$ test, placebo (PLA), and glutamine (GLN) trials. Three exercise trials were separated by 2 -week intervals. After the $\mathrm{VO}_{2 \max }$ test, the participants were invited to complete PLA and GLN trials at the Integrated Environment and Exercise Laboratory (China Institute of Sport Science). In each main trial (PLA or GLN trial), participants ingested a GLN or PLA ingestion prior to exercise, and then performed treadmill running at $40 \% \mathrm{VO}_{2 \max }$ to exhaustion (heart rate $>180$ beats $/$ min, core body temperature $>39^{\circ} \mathrm{C}$, and subjective complaints of discomfort) in a chamber set at $38 \pm 1{ }^{\circ} \mathrm{C}, 60 \pm 5 \%$ relative humidity, and 
$20.8 \%$ oxygen. Heart rate $(\mathrm{HR})$, core body temperature $\left(\mathrm{T}_{\mathrm{GI}}\right)$, forehead temperature $\left(\mathrm{T}_{\mathrm{FH}}\right)$, and rating of perceived exertion (RPE) were recorded continually during exercise. Moreover, seated posture-controlled venous blood samples were collected before glutamine ingestion and immediately after exercise. Nude body weight was also measured to reflect dehydration. All data collection was completed during the winter (January and February) to eliminate the influence of thermal adaptation, and all subjects were instructed to maintain their regular diets throughout the experiment.

$V \boldsymbol{O}_{2 \max }$ test

The $\mathrm{VO}_{2 \max }$ of each participant was determined using a computer-controlled treadmill $(\mathrm{h} / \mathrm{p} / \mathrm{cosmos}$, Nussdorf-Traunstein, Germany) according to the Bruce treadmill test protocol, with a warm-up on the treadmill before data collection. Speed and the incline were elevated every 3 min from a comfortable pace of $2.7 \mathrm{~km} / \mathrm{h}$ at an incline of $10 \%$ up to a point where the participants felt unable to continue the protocol under strong verbal encouragement. The $\mathrm{VO}_{2 \max }$, oxygen uptake, ventilation, HR, and respiratory exchange ratio (RER) were monitored during the test using a Cortex Metamax 3B gas-analysis system (Biophysik, Leipzig, Germany). The criteria for attaining $\mathrm{VO}_{2 \max }$ included the participant reaching volitional exhaustion, an HR of 180 beats/min or the age-predicted maximum $\mathrm{HR}$, the presence of $\mathrm{VO}_{2}$ plateau and an RER of 1.15 or above (Poole et al., 2008).

\section{Glutamine and placebo ingestion}

Thirty minutes prior to treadmill exercise in the heat, participants ingested $0.6 \mathrm{~g} / \mathrm{kg}$ body weight of L-glutamine (Competitor Sports Science \& Tech, Beijing, China) mixed with sugar-free lemon drink in GLN trial, and an equal amount of the sugar-free lemon drink alone in the PLA trial (Ziegler et al., 1990; Gleeson, 2008). 


\section{Homeostatic measurements}

A CorTemp ${ }^{\mathrm{TM}}$ Wireless Sensing System (HQ Inc., Palmetto, FL, USA) including a wireless core body temperature monitoring data recorder and pill-shaped ingestible core body temperature sensor, was employed to monitor the gastrointestinal temperature $\left(\mathrm{T}_{\mathrm{GI}}\right)$ of participants during exercise. Participants were required to swallow the sensor 4 hours prior to the measurements to make sure that the sensors reached the right position of the digestive tract. An FR-1DZ1 Electronic Thermometer (Mcirolife, Widnau, Switzerland) was used to assess the infrared temperature of the forehead $\left(\mathrm{T}_{\mathrm{FH}}\right)$ during exercise. Moreover, continuous HR data were recorded by using a Polar RS800 Heart Rate Monitor (Polar, Kempele, Finland), while the nude and dry body weight of participants were measured before and after exercise by using a TY-2003A Electronic Weight Scale (Yite, Wuhan, China).

\section{Blood sampling and analysis}

Seated posture-controlled venous blood samples were collected at pre- and immediately postexercise using a standard venipuncture technique. Blood samples collected in heparinized tubes were used to perform the lymphocyte subsets analysis (total lymphocyte count; absolute count and percentage of $\mathrm{CD} 3+, \mathrm{CD} 19+, \mathrm{CD} 3+\mathrm{CD} 4+, \mathrm{CD} 3+\mathrm{CD} 8+$, and $\mathrm{CD} 3-\mathrm{CD} 16+\mathrm{CD} 56+$; and $\mathrm{CD} 4+/ \mathrm{CD} 8+$ ) using the ACEA NovoCyteTM Flow Cytometry System (ACEA Biosciences, San Diego, CA, USA). Hematologic parameters (white blood cell [WBC]; red blood cell [RBC]; hemoglobin [HGB]; hematocrit $[\mathrm{HCT}]$; mean corpuscular volume [MCV]; mean corpuscular hemoglobin concentration $[\mathrm{MCHC}]$; mean corpuscular hemoglobin $[\mathrm{MCH}]$; red blood cell distribution width-variation coefficient [RDW-CV]; red blood cell distribution width-standard deviation [RDW-SD]; platelet counts [PLT]; platelet distribution width [PDW]; mean platelet volume [MPV]; plateletcrit [PCT]; 
and absolute count and percentage of neutrophils [NEU]; lymphocytes [LYM]; eosinophils [EOS]; basophils $[\mathrm{BAS}]$; and monocytes $[\mathrm{MON}])$ using the BC-5180 Automatic Blood Cell Analyzer (Mindary, Shenzhen, China). Moreover, the serum samples separated from additional blood samples without anticoagulant were used to assess the immunoglobulins (IgG, $\operatorname{IgA}$, and $\operatorname{IgM}$ ) and complements (C3 and C4) using the Roche Cobas c501 Chemistry Analyzer (Roche Diagnostics, Indianapolis, IN, USA), and interleukin (IL)-2, IL-6, tumor necrosis factor-alpha (TNF- $\alpha$ ), and hydroxyl radical $(\mathrm{OH})$ by using commercial kits (Beijing SINO-UK Institute of Biological Technology, Beijing, China) with the Stat Fax 2100 Microplate Reader (Awareness Technology, Inc., Palm City, FL, USA). All of these biochemical analyses were completed by experienced testers, according to the manufactures' procedures. Then all data obtained from blood and plasma were adjusted for percentage changes in plasma volume (\% $\Delta \mathrm{PV})$ by using Van Beaumont's Equation: $\% \Delta \mathrm{PV}=\left[100 /\left(100-\mathrm{HCT}_{\mathrm{PRE}}\right)\right] \times\left[\left(100\left(\mathrm{HCT}_{\mathrm{PRE}}-\mathrm{HCT}_{\mathrm{POST}}\right) / \mathrm{HCT}_{\mathrm{POST}}\right] \quad\left(\mathrm{HCT}_{\mathrm{PRE}}=\right.\right.$ hematocrit value at pre-exercise; $\mathrm{HCT}_{\mathrm{POST}}=$ hematocrit value at post-exercise) and Correction formula: Corrected value $=$ Uncorrected value $\mathrm{x}[(100+\% \Delta \mathrm{PV}) / 100]$ before further analysis.

\section{Statistical analysis}

All results are expressed as means \pm standard deviation (SD). All measurements were analyzed using two conditions (PLA vs. GLN) by two time points (pre- and post-exercise) two-way analysis of variance (ANOVA) with repeated measures (RM). If a significant F-value was observed $(\mathrm{p}<0.05)$, paired and independent t-test were used for within groups (two time points) and between groups (two conditions) comparisons. Pearson correlation was also applied in this study to determine the correlation between homeostatic and immune parameters. Analyses were performed using SPSS software version 13.0 (SPSS Inc., Chicago, USA). A two-tailed P-value of $<0.05$ was considered statistically significant. 


\section{Results}

\section{Homeostatic and hematologic parameters}

No differences in baseline measurements and exercise time to fatigue were found between groups $(p>0.05)$. However, there was a significant main effect of time $(p<0.01)$ but not condition $(p>0.05)$ on HR, $\mathrm{T}_{\mathrm{GI}}, \mathrm{T}_{\mathrm{FH}}, \mathrm{RPE}$, and body weight in both PLA and GLN groups during exhaustive exercise in the heat (Table 1 and Fig. 1). Moreover, $\mathrm{T}_{\mathrm{GI}}$ showed a strong correlation with HR throughout the exercise period in both PLA $(\mathrm{r}=0.953, \mathrm{p}<0.01)$ and GLN $(\mathrm{r}=0.938, \mathrm{p}<0.01)$ groups. There was also a significant main effect of time $(p<0.05)$ but not condition $(p>0.05)$ on WBC, NEU, LYM, RBC, HGB, HCT, PLT, and PCT, all of which were significantly elevated $(p<0.05)$, whereas on EOS\%, MON\%, MCV, MCH, RDW-CV, RDW-SD, and PDW were significantly decreased $(\mathrm{p}<0.05)$ following exercise in the heat. In addition, $\mathrm{BAS} \%$ and $\mathrm{MCHC}$ only increased post-exercise in the PLA group $(p<0.05)$, whereas MPV only increased in the GLN group $(p<0.05)$ with a main effect of time $(\mathrm{p}<0.05)$. No statistically significant effect of time and condition were observed in NEU\%, LYM\%, EOS, BAS, and MON (p>0.05) (Table 2).

\section{Immune and inflammatory parameters}

There was a significant interaction effect of condition $\times$ time on absolute count of CD3+ lymphocytes (RM ANOVA, $\mathrm{F}=4.26, \mathrm{p}<0.05)$ and absolute count of $\mathrm{CD} 3+\mathrm{CD} 8+$ lymphocytes $(\mathrm{RM}$ ANOVA, $F=4.27, p<0.05)$, which were only significantly elevated $(\mathrm{p}<0.05)$ in the GLN group in response to exercise in the heat (Table 3 and Fig. 2). Moreover, there was a potential interaction effect of condition $\times$ time on the absolute count of CD3+CD4+ lymphocytes (RM ANOVA, F=3.21, $\mathrm{p}=0.08$ ), but it did not reach statistical significance. No interaction effects condition $\times$ time or main effect of condition was observed in the other parameters of lymphocyte subsets $(p>0.05)$. However, 
a significant main effect of time $(\mathrm{p}<0.05)$ was observed in $\mathrm{CD} 3+\%, \mathrm{CD} 19+\%, \mathrm{CD} 3+\mathrm{CD} 4+\%$, and CD4/CD8, which significantly decreased $(\mathrm{p}<0.05)$, whereas absolute count and percentage of NK, which increased significantly $(\mathrm{p}<0.01)$ in both PLA and GLN groups following exercise in the heat (Table 3). A statistically significant correlation (PLA vs. GLN: $r=0.665, \mathrm{p}<0.05$ vs. $\mathrm{r}=0.553, \mathrm{p}<0.05$ ) was also found between the absolute count of NK cells and HR immediately after exercise in the heat. In addition, there was a significant main effect of time $(p<0.05)$ but not condition $(p>0.05)$ on immunoglobulins and complements, whereby $\operatorname{IgG}, \operatorname{IgA}, \operatorname{IgM}, \mathrm{C} 3$, and $\mathrm{C} 4$ were significantly elevated $(p<0.05)$ in the PLA group and IgG significantly increased $(p<0.01)$ in the GLN groups post-exercise in the heat (Table 4). No statistically significant main or interaction effects of time and condition were found in IL-2, IL-6, TNF- $\alpha$, and OH ( $>0.05)$ (Table 5).

\section{Discussion}

The major finding of this study was that acute glutamine ingestion prior to exercise evoked CD3+ T and $\mathrm{CD} 3+\mathrm{CD} 8+\mathrm{T}$ cell lymphocytosis immediately after exhaustive exercise in the heat compared with consuming a placebo beverage. However, no treatment effects of glutamine were evident in hemostatic, hematologic, inflammatory, and other immune responses to exhaustive exercise in the heat. To the best of our knowledge, the present study is the first to show that acute glutamine ingestion before exercise would boost the mobilization of $\mathrm{T}$ cell lymphocytes into the peripheral blood following exhaustive exercise in the heat.

It has been previously demonstrated that exercise in the heat as a multi-stress situation elicits a larger leukocytosis, which mainly comprises granulocytosis and lymphocytosis but not the monocytosis, in comparison to exercise in a temperate or cool environment (Cross et al., 1996; Rhind et al., 1999). In agreement with previous studies, remarkable leukocytosis that included 
neutrophil granulocytosis (neutrophilia) and NK cell lymphocytosis were identified immediately after exhaustive exercise under heat stress in the current study. Using 'thermal clamp' models, several studies have previously indicated that as much as half of these leukocytic responses, especially the neutrophil granulocytosis, are associated with a higher increment in core body temperature during exercise in the heat than that in a temperate condition (Cross et al., 1996; Walsh \& Whitham, 2006). Therefore, a significantly increased core body temperature $\left(\sim 39.5^{\circ} \mathrm{C}\right)$ in this study partly accounts for the leukocytosis in response to exhaustive exercise in the heat. The mechanism behind this may be the elevated stress hormones, which serve as key regulators of leukocyte trafficking and activation of immune cells, evoked by rapidly increased body temperature under exercise and heat stress (Niess et al., 2003).

In addition, it is well documented that the increased shear stress and cardiac output during exercise in the heat also drive more leukocytes into the bloodstream (Gleeson et al., 2013). Besides a significant increment in HR was evident in the present study, a positive correlation $(r=0.665$, $\mathrm{p}<0.05$ ) between the absolute count of NK cells and HR was identified indicating that cardiovascular drift specifically regulates the NK cell lymphocytosis after exhaustive exercise in the heat. Collectively, it appears clear that neutrophils and NK cells are sensitive to thermal as well as cardiovascular responses to exhaustive exercise in the heat. These nonspecific quick-response immune cells, as major subpopulations of innate immune system, may contribute to the elimination of pathogens and further adaptive immune activities in responses to exhaustive exercise in the heat (Pyne, 1994; Vivier et al., 2008).

Glutamine as one of typical 'immuno-nutrients' has been widely used in exercise or hyperthermiainduced alterations in the immune system. In previous animal studies, acute glutamine ingestion 
before exercise could prevent exercise-induced neutrophil apoptosis and dysfunction in the rat (Lagranha et al., $2004 \&$ 2005). Nevertheless, no effects of glutamine intake have been detected in the absolute counts and percentage of neutrophil and NK cells after prolonged exercise in human subjects (Walsh et al., 2000; Krzywkowski et al., 2001). In the present study, acute glutamine ingestion also showed no favorable or harmful effects on the number of circulating neutrophils and NK cells following exhaustive exercise in the heat. It may be that glutamine has no impacts on increased body temperature-induced stress hormones, which is the potential underlying mechanism of recruiting innate immune cells during exercise in the heat as previously discussed (Gleeson \& Bishop, 2000). Furthermore, acute glutamine ingestion also did not change the body temperature and HR in the current study in accordance with previous studies (Zuhl et al., 2014). Therefore, the thermal and cardiovascular response-mediated neutrophilia and NK cell lymphocytosis after exhaustive exercise in the heat may not be affected by acute intake of glutamine.

On the other hand, $\mathrm{T}$ and $\mathrm{B}$ lymphocytes mediate the adaptive immune system including cellular and humoral immune responses, which are also regulated by exercise and hyperthermia. As mentioned in the majority of previous studies, CD3+CD4+ lymphocytes and ratio of CD4+/CD8+ (helper/suppressor) would decrease under heavy stress, such as strenuous exercise and hyperthermia, suggesting disturbances in the adaptive immune system (Herbert \& Cohen, 1993; Steensberg et al., 2001). However, the elevation in CD3+CD8+ lymphocytes was found in exercise and mild-heating, in contrast, a decreased percentage of $\mathrm{CD} 3+\mathrm{CD} 8+$ can be found in acute heatstroke patient (Bouchama et al., 1992; Dieing et al., 2003; Turner et al., 2010). Accordingly, T cell lymphocytic responses to exercise in the heat remain controversial (Walsh \& Whitham, 2006). In this study, declines in the percentage but not the absolute count of $\mathrm{CD} 3+, \mathrm{CD} 3+\mathrm{CD} 4+$ (helper/inducer), $\mathrm{CD} 3+\mathrm{CD} 8+$ (suppressor/cytotoxic), and CD4+/CD8+ were observed, which presents immune 
phenotypes of heatstroke. However, significantly elevated absolute counts and percentage of NK cells was also found in the present study. It is possible that the changes in the percentage of these lymphocyte subsets in response to exhaustive exercise in the heat is, at least partly, a result of greatly increased NK cells in the peripheral blood. In addition, the absolute counts and percentage of B (CD19+) lymphocytes also declined after exhaustive exercise in the heat. Generally, B lymphocyte would increase immediately after exercise and hyperthermia and subsequently reduce during the recovery period (Wolach et al., 1998, Chen et al., 2006). Moreover, a decreased percentage of CD19+ was observed in acute heatstroke and excessive heat exposure (Bouchama et al., 1992; Hammami et al., 1998). Thus, it also suggests a heatstroke-like immune disturbance in the adaptive immune system after exhaustive exercise in the heat. Furthermore, the increased immunoglobulins (IgA, $\operatorname{IgG}$, and $\operatorname{IgM}$ ) and complements (C3 and $\mathrm{C} 4)$ were found following exercise in the heat in the present study, though the impaired B lymphocytes may lead to dysfunction of humoral immune responses. It is possible due to the redistribution of immunoglobulins and complements from the other parts of human body (Janeway et al., 2001).

It is well known that glutamine is essential 'fuel' for T lymphocytes proliferation, and provision of glutamine is considered beneficial for impaired lymphocyte proliferation in the situation of heavy or prolonged exercise (Yaqoob \& Calder, 1997; Castell, 2003). Moreover, a clinical study also showed that glutamine-supplemented total parenteral nutrition (TPN) enhances the T-cell responses in postoperative patients compared with consuming a control TPN (O'riordain et al., 1994). Therefore, glutamine ingestion may be an 'immuno-nutrition' for adaptive immune cells of people suffering stress. Nevertheless, the influence of glutamine in immune system under heat stress remains unknown. In this study, with the acute ingestion of glutamine before exhaustive exercise in the heat, immune disturbances, such as B cell lymphopenia and reduced ratio of CD4+/CD8+, were not 
altered. However, it is noteworthy that acute glutamine ingestion-induced CD3+ and CD3+CD8+ T lymphocytosis in response to exhaustive exercise in the heat were identified in this study. Our finding suggests that glutamine ingestion may enhance the $\mathrm{T}$ cell response to exercise in the heat specifically through up-regulating the mobilization of CD3+CD8+ T lymphocyte, which is similar with previously mentioned studies.

Furthermore, the inflammatory cytokines including IL-2, IL-6, and TNF- $\alpha$, which are mediators of leukocytes trafficking, were measured in this study to investigate the potential mechanism underlying acute glutamine ingestion-induced T lymphocytosis (Schall \& Bacon, 1994). On the basis of current knowledge, cytokines released from skeletal muscle and immune cells during heavy exercise could be exacerbated by additional heat stress and abolished by thermal clamp (Rhind et al., 2004; Fortes et al., 2013). However, hyperthermia alone or low-dosage exercise is insufficient to evoke the sufficient production of cytokines (Kappel et al., 1995; Peake et al., 2005). In the present study, inflammatory cytokines remain unchanged following exercise in the heat, which possibly due to the low-intensity $\left(40 \% \mathrm{VO}_{2 \max }\right)$ and short-duration $(\sim 40 \mathrm{~min})$ treadmill exercise pose inadequate physical stress to the skeletal muscle and immune cells. In accordance with our results, a previous study has shown that no significant changes of IL-6 and TNF- $\alpha$ were observed at 45 min during prolonged cycling in the heat, while significant increases occurred at 90 min (Starkie et al., 2005). In addition, a moderate hyperthermia could delay the production of cytokines by peripheral blood mononuclear cells (PBMCs), which may also account for the unchanged cytokines during exercise in the heat (Kimura et al., 2002).

On the other hand, the cytokines production is also regulated by glutamine hemostasis (Roth, 2008). Acute glutamine consumption has shown its favorable effects on reduction of TNF- $\alpha$ at $4 \mathrm{~h}$ after 
exercise, though no significant changes were found immediately after exercise (Zuhl et al., 2015). Moreover, a higher level of IL-6 has been reported immediately after $2 \mathrm{~h} 75 \% \mathrm{VO}_{2 \max }$ exercise with glutamine intervention (Hiscock et al., 2003). Up to date, few studies on cytokines induction during exercise have been investigated with glutamine intervention, especially in adverse environments. In this study, no treatment effects of glutamine ingestion on cytokines induction have been found immediately after exercise in the heat. As described in previously mentioned studies, it seems that the cytokines affected by glutamine is duration dependent. Additionally, the increased utilization of glutamine in the synthesis of heat shock proteins (HSPs) in PBMCs may result in a relative glutamine depletion and delayed cytokines production during exercise in the heat (Zuhl et al., 2014).

The potential underlying mechanism of acute glutamine ingestion-induced $\mathrm{T}$ lymphocytosis has been reviewed previously (de Oliveira et al., 2016). It primarily covers HSPs, nuclear factor kappa B (NF-kB), mitogen-activated protein kinases (MAPKs), and adhesion molecules (cell migration) pathways. A recent study has shown that acute glutamine ingestion could activate the HSPs in PBMCs and subsequently decrease the exercise-induced PBMCs apoptosis via NF-kB pathways (Zuhl et al., 2014 \& 2015). In addition, MAPKs signaling pathways also involve in glutamineregulated lymphocytes apoptosis and proliferation (Carr et al., 2010). However, these molecular pathways could be found in all phenotypes of leukocytes. Therefore, no responses of other subpopulations of leukocytes to glutamine ingestion in the present study indicated that activation or inactivation of HSPs, NF-kB, and MAPKs may not contribute to the selective $\mathrm{T}$ lymphocytosis induced by glutamine. On the other hand, CD11a and CD11b, two well-known adhesion molecules, mediate the lymphocyte trafficking under stressful situations (Viswanathan \& Dhabhar, 2005). While a previous study indicated that lymphocyte trafficking was not regulated by glutamine supplementation during exercise, another study using a mice model of acute colitis found that 
glutamine ingestion decreased the adhesion molecules and chemokines in $\mathrm{T}$ lymphocytes (Krzywkowski et al., 2001; Hou et al., 2014). Most previous studies suggested that glutamine could reduce leukocytes infiltration to the tissues (de Oliveira et al., 2016). Therefore, T lymphocytosis in this study evoked by glutamine is possible through inhibition of the exercise and heat stressrecruited lymphocyte infiltrate back to the tissues. However, the selective effects of glutamine on T lymphocytes mobilization during exhaustive exercise in the heat remain further understanding.

In summary, this study has demonstrated that exhaustive exercise in the heat evokes leukocytosis, which mainly comprises the neutrophil granulocytosis and NK cell lymphocytosis; immune disturbances induced by exhaustive exercise in the heat are characterized by reduced CD4+/CD8+ ratio and $\mathrm{B}$ lymphopenia; and acute glutamine ingestion can induce $\mathrm{CD} 3+$ and $\mathrm{CD} 3+\mathrm{CD} 8+\mathrm{T}$ cell lymphocytosis in response to exhaustive exercise in the heat, while it had no effects on hemostatic, hematologic, inflammatory or other immune parameters. These findings suggest that acute glutamine ingestion is a potential method for boosting leukocyte trafficking and subsequently improving the immune functions in athletes, sports enthusiast, fire fighter, and military personnel in response to exhaustive physical exercise in the heat.

\section{Acknowledgements}

The authors thank all volunteers who participated in this study. Thanks to Prof. Zhang Yimin from Beijing Sport University for his valuable help on $\mathrm{VO}_{2 \max }$ test. Thanks to Dr. Feng Wenping from China Institute of Sport Science for her valuable help on exercise trials in the heat.

\section{Author's contribution}


$\mathrm{CZ}, \mathrm{XC}$, and $\mathrm{YZ}$ conceived and designed the study. $\mathrm{CZ}, \mathrm{XC}$, and $\mathrm{YZ}$ performed the experiments. $\mathrm{CZ}$ and $\mathrm{XC}$ wrote the paper. $\mathrm{YZ}$ reviewed and edited the manuscript. All authors read and approved the manuscript.

\section{Conflict of interest}

The authors declare that we have no conflict of interest.

\section{References}

Ahlers, O., Hildebrandt, B., Dieing, A., Deja, M., Bohnke, T., Wust, P., Riess, H., Gerlach, H., and Kerner, T. 2005. Stress induced changes in lymphocyte subpopulations and associated cytokines during whole body hyperthermia of 41.8-42.2 degrees C. Eur. J. Appl. Physiol. 95(4): 298-306. doi:10.1007/s00421-005-0009-4.

Boelens, P.G., Fonk, J.C., Houdijk, A.P., Scheper, R.J., Haarman, H.J., Meijer, S., Van Leeuwen, P.A., and von Blomberg-van der Flier, B.M. 2004. Primary immune response to keyhole limpet haemocyanin following trauma in relation to low plasma glutamine. Clin. Exp. Immunol. 136(2): 356-364. doi:10.1111/j.1365-2249.2004.02447.x.

Bouchama, A., al Hussein, K., Adra, C., Rezeig, M., al Shail, E., and al Sedairy, S. 1992. Distribution of peripheral blood leukocytes in acute heatstroke. J. Appl. Physiol. (1985) 73(2): 405409.

Bunpo, P., Murray, B., Cundiff, J., Brizius, E., Aldrich, C.J., and Anthony, T.G. 2008. Alanylglutamine consumption modifies the suppressive effect of L-asparaginase on lymphocyte populations in mice. J. Nutr. 138(2): 338-343. 
Butcher, E.C., Williams, M., Youngman, K., Rott, L., and Briskin, M. 1999. Lymphocyte trafficking and regional immunity. Adv. Immunol. 72: 209-253. doi: 10.1016/S00652776(08)60022-X.

Caris, A.V., Lira, F.S., de Mello, M.T., Oyama, L.M., and dos Santos, R.V. 2014. Carbohydrate and glutamine supplementation modulates the Th1/Th2 balance after exercise performed at a simulated altitude of $4500 \mathrm{~m}$. Nutrition, 30(11-12): 1331-1336. doi:10.1016/j.nut.2014.03.019.

Carr, E.L., Kelman, A., Wu, G.S., Gopaul, R., Senkevitch, E., Aghvanyan, A., Turay, A.M., and Frauwirth, K.A. 2010. Glutamine uptake and metabolism are coordinately regulated by ERK/MAPK during T lymphocyte activation. J. Immunol. 185(2): 1037-1044. doi:10.4049/jimmunol.0903586.

Castell, L. 2003. Glutamine supplementation in vitro and in vivo, in exercise and in immunodepression. Sports Med. 33(5): 323-345.

Castell, L.M., Poortmans, J.R., and Newsholme, E.A. 1996. Does glutamine have a role in reducing infections in athletes? Eur. J. Appl. Physiol. Occup. Physiol. 73(5): 488-490.

Chen, Q., Fisher, D.T., Clancy, K.A., Gauguet, J.M., Wang, W.C., Unger, E., Rose-John, S., von Andrian, U.H., Baumann, H., and Evans, S.S. 2006. Fever-range thermal stress promotes lymphocyte trafficking across high endothelial venules via an interleukin 6 trans-signaling mechanism. Nat. Immunol. 7(12): 1299-1308. doi:10.1038/ni1406.

Cross, M.C., Radomski, M.W., VanHelder, W.P., Rhind, S.G., and Shephard, R.J. 1996. Endurance exercise with and without a thermal clamp: effects on leukocytes and leukocyte subsets. J. Appl. Physiol. (1985) 81(2): 822-829. 
de Oliveira, D.C., da Silva Lima, F., Sartori, T., Santos, A.C.A., Rogero, M.M., and Fock, R.A. 2016. Glutamine metabolism and its effects on immune response: molecular mechanism and gene expression. Nutrire, 41: 14. doi:10.1186/s41110-016-0016-8.

Dieing, A., Ahlers, O., Kerner, T., Wust, P., Felix, R., Loffel, J., Riess, H., and Hildebrandt, B. 2003. Whole body hyperthermia induces apoptosis in subpopulations of blood lymphocytes. Immunobiology, 207(4): 265-273. doi:10.1078/0171-2985-00236.

Fortes, M.B., Di Felice, U., Dolci, A., Junglee, N.A., Crockford, M.J., West, L., Hillier-Smith, R., Macdonald, J.H., and Walsh, N.P. 2013. Muscle-damaging exercise increases heat strain during subsequent exercise heat stress. Med. Sci. Sports Exerc. 45(10): 1915-1924. doi:10.1249/MSS.0b013e318294b0f8.

Gleeson, M. 2008. Dosing and efficacy of glutamine supplementation in human exercise and sport training. J. Nutr. 138(10): 2045S-2049S.

Gleeson, M., Bishop, N., and Walsh, N. 2013. Exercise immunology. Routledge (Taylor and Francis), London.

Gleeson, M. and Bishop, N.C. 2000. Special feature for the Olympics: effects of exercise on the immune system: modification of immune responses to exercise by carbohydrate, glutamine and anti-oxidant supplements. Immunol. Cell. Biol. 78: 554-561. doi:10.1111/j.1440-1711.2000.t01-6. $\mathrm{x}$.

Hammami, M.M., Bouchama, A., Shail, E., Aboul-Enein, H.Y., and Al-Sedairy, S. 1998. Lymphocyte subsets and adhesion molecules expression in heatstroke and heat stress. J. Appl. Physiol. (1985) 84(5): 1615-1621.

Herbert, T.B. and Cohen, S. 1993. Stress and immunity in humans: a meta-analytic review. Psychosom. Med. 55(4): 364-379. 
Hiscock, N. and Pedersen, B.K. 2002. Exercise-induced immunodepression- plasma glutamine is not the link. J. Appl. Physiol. (1985) 93(3): 813-822. doi:10.1152/japplphysiol.00048.2002.

Hiscock, N., Petersen, E.W., Krzywkowski, K., Boza, J., Halkjaer-Kristensen, J., and Pedersen, B.K. 2003. Glutamine supplementation further enhances exercise-induced plasma IL-6. J. Appl. Physiol. (1985) 95(1): 145-148. doi:10.1152/japplphysiol.00471.2002.

Holecek, M. 2013. Side effects of long-term glutamine supplementation. JPEN J. Parenter. Enteral. Nutr. 37(5): 607-616. doi:10.1177/0148607112460682.

Hou, Y.C., Wu, J.M., Wang, M.Y., Wu, M.H., Chen, K.Y., Yeh, S.L., and Lin, M.T. 2014. Glutamine supplementation attenuates expressions of adhesion molecules and chemokine receptors on T cells in a murine model of acute colitis. Mediators Inflamm. 2014: 837107. doi:10.1155/2014/837107.

Janeway, C.A., Travers, P., Walport, M., and Capra, J.D. 2001. Immunobiology: The Immune System in Health and Disease. Garland Science, New York.

Kappel, M., Tvede, N., Hansen, M.B., Stadeager, C., and Pedersen, B.K. 1995. Cytokine production ex vivo: effect of raised body temperature. Int. J. Hyperthermia, 11(3): 329-335.

Kimura, A., Sakurada, S., Ohkuni, H., Todome, Y., and Kurata, K. 2002. Moderate hypothermia delays proinflammatory cytokine production of human peripheral blood mononuclear cells. Crit. Care Med. 30(7): 1499-1502.

Krieger, J.W., Crowe, M., and Blank, S.E. 2004. Chronic glutamine supplementation increases nasal but not salivary IgA during 9 days of interval training. J. Appl. Physiol. (1985) 97(2): 585-591. doi:10.1152/japplphysiol.00971.2003.

Kruger, K., Lechtermann, A., Fobker, M., Volker, K., and Mooren, F.C. 2008. Exerciseinduced redistribution of T lymphocytes is regulated by adrenergic mechanisms. Brain Behav. Immun. 22(3): 324-338. doi:10.1016/j.bbi.2007.08.008. 
Krzywkowski, K., Petersen, E.W., Ostrowski, K., Kristensen, J.H., Boza, J., and Pedersen, B.K. 2001. Effect of glutamine supplementation on exercise-induced changes in lymphocyte function. Am. J. Physiol. Cell Physiol. 281(4): C1259-1265.

Lagranha, C.J., de Lima, T.M., Senna, S.M., Doi, S.Q., Curi, R., and Pithon-Curi, T.C. 2005. The effect of glutamine supplementation on the function of neutrophils from exercised rats. Cell Biochem. Funct. 23(2): 101-107. doi:10.1002/cbf.1192.

Lagranha, C.J., Senna, S.M., de Lima, T.M., Silva, E., Doi, S.Q., Curi, R., and Pithon-Curi, T.C. 2004. Beneficial effect of glutamine on exercise-induced apoptosis of rat neutrophils. Med. Sci. Sports Exerc. 36(2): 210-207. doi:10.1249/01.MSS.0000113490.98089.B1.

Niess, A.M., Fehrenbach, E., Lehmann, R., Opavsky, L., Jesse, M., Northoff, H., and Dickhuth, H.H. 2003. Impact of elevated ambient temperatures on the acute immune response to intensive endurance exercise. Eur. J. Appl. Physiol. 89(3-4): 344-351. doi:10.1007/s00421-003-0809-3.

O'Riordain, M.G., Fearon, K.C., Ross, J.A., Rogers, P., Falconer, J.S., Bartolo, D.C., Garden, O.J., and Carter, D.C. 1994. Glutamine-supplemented total parenteral nutrition enhances Tlymphocyte response in surgical patients undergoing colorectal resection. Ann. Surg. 220(2): 212221.

Peake, J.M., Suzuki, K., Hordern, M., Wilson, G., Nosaka, K., and Coombes, J.S. 2005. Plasma cytokine changes in relation to exercise intensity and muscle damage. Eur. J. Appl. Physiol. 95(5-6): 514-521. doi:10.1007/s00421-005-0035-2.

Pedersen, L., Idorn, M., Olofsson, G.H., Lauenborg, B., Nookaew, I., Hansen, R.H., Johannesen, H.H., Becker, J.C., Pedersen, K.S., Dethlefsen, C., Nielsen, J., Gehl, J., Pedersen, B.K., Thor Straten, P., and Hojman, P. 2016. Voluntary Running Suppresses Tumor Growth through Epinephrine- and IL-6-Dependent NK Cell Mobilization and Redistribution. Cell Metab. 23(3): 554-562. doi:10.1016/j.cmet.2016.01.011. 
Pollheimer, J., Zellner, M., Eliasen, M.M., Roth, E., and Oehler, R. 2005. Increased susceptibility of glutamine-depleted monocytes to fever-range hyperthermia: the role of $70-\mathrm{kDa}$ heat shock protein. Ann. Surg. 241(2): 349-355.

Poole, D.C., Wilkerson, D.P., and Jones, A.M. 2008. Validity of criteria for establishing maximal O2 uptake during ramp exercise tests. Eur. J. Appl. Physiol. 102(4): 403-410. doi:10.1007/s00421-007-0596-3.

Pyne, D.B. 1994. Regulation of neutrophil function during exercise. Sports Med. 17(4): 245258.

Rezende Freitas, H., da Silva Pereira, A., and da Silva Ramos, T. 2015. The Effects of Acute/Chronic Glutamine and Glutamine Peptide Supplementation on the Performance and Immune Function in Young Active Adult Athletes. Curr. Nutr. Food Sci. 11(4): 315-322. doi: $10.2174 / 1573401311666150729225554$.

Rhind, S.G., Gannon, G.A., Shek, P.N., Brenner, I.K., Severs, Y., Zamecnik, J., Buguet, A., Natale, V.M., Shephard, R.J., and Radomski, M.W. 1999. Contribution of exertional hyperthermia to sympathoadrenal-mediated lymphocyte subset redistribution. J. Appl. Physiol. (1985) 87(3): $1178-1185$.

Rhind, S.G., Gannon, G.A., Shephard, R.J., Buguet, A., Shek, P.N., and Radomski, M.W. 2004. Cytokine induction during exertional hyperthermia is abolished by core temperature clamping: neuroendocrine regulatory mechanisms. Int. J. Hyperthermia, 20(5): 503-516. doi:10.1080/02656730410001670651.

Rohde, T., Krzywkowski, K., and Pedersen, B.K. 1998. Glutamine, exercise, and the immune system--is there a link? Exerc. Immunol. Rev. 4: 49-63.

Roth, E. 2008. Nonnutritive effects of glutamine. J. Nutr. 138(10): 2025S-2031S. 
Schall, T.J. and Bacon, K.B. 1994. Chemokines, leukocyte trafficking, and inflammation. Curr. Opin. Immunol. 6(6): 865-873.

Simpson, R.J. 2011. Aging, persistent viral infections, and immunosenescence: can exercise "make space"? Exerc. Sport Sci. Rev. 39(1): 23-33. doi:10.1097/JES.0b013e318201f39d.

Simpson, R.J., Cosgrove, C., Chee, M.M., McFarlin, B.K., Bartlett, D.B., Spielmann, G., O'Connor, D.P., Pircher, H., and Shiels, P.G. 2010. Senescent phenotypes and telomere lengths of peripheral blood T-cells mobilized by acute exercise in humans. Exerc. Immunol. Rev. 16: 40-55.

Singleton, K.D. and Wischmeyer, P.E. 2006. Oral glutamine enhances heat shock protein expression and improves survival following hyperthermia. Shock, 25(3): 295-299. doi:10.1097/01.shk.0000196548.10634.02.

Sprent, J. and Tough, D.F. 1994. Lymphocyte Life-Span and Memory. Science, 265(5177): 1395-1400. doi:10.1126/science.8073282.

Starkie, R.L., Hargreaves, M., Rolland, J., and Febbraio, M.A. 2005. Heat stress, cytokines, and the immune response to exercise. Brain Behav. Immun. 19(5): 404-412. doi:10.1016/j.bbi.2005.03.005.

Steensberg, A., Toft, A.D., Bruunsgaard, H., Sandmand, M., Halkjaer-Kristensen, J., and Pedersen, B.K. 2001. Strenuous exercise decreases the percentage of type $1 \mathrm{~T}$ cells in the circulation. J. Appl. Physiol. (1985) 91(4): 1708-1712.

Turner, J.E., Aldred, S., Witard, O.C., Drayson, M.T., Moss, P.M., and Bosch, J.A. 2010. Latent cytomegalovirus infection amplifies CD8 T-lymphocyte mobilisation and egress in response to exercise. Brain Behav. Immun. 24(8): 1362-1370. doi:10.1016/j.bbi.2010.07.239.

Viswanathan, K. and Dhabhar, F.S. 2005. Stress-induced enhancement of leukocyte trafficking into sites of surgery or immune activation. Proc. Natl. Acad. Sci. U S A 102(16): 5808-5813. doi:10.1073/pnas.0501650102. 
Vivier, E., Tomasello, E., Baratin, M., Walzer, T., and Ugolini, S. 2008. Functions of natural killer cells. Nat. Immunol. 9(5): 503-510. doi:10.1038/ni1582.

Walsh, N. P., Blannin, A. K., Bishop, N. C., Robson, P. J., and Gleeson, M. 2000. Effect of oral glutamine supplementation on human neutrophil lipopolysaccharide-stimulated degranulation following prolonged exercise. Int. J. Sport Nutr. Exerc. Metab. 10(1): 39-50.

Walsh, N.P., Blannin, A.K., Robson, P.J., and Gleeson, M. 1998. Glutamine, exercise and immune function. Links and possible mechanisms. Sports Med. 26(3): 177-191.

Walsh, N.P. and Whitham, M. 2006. Exercising in environmental extremes : a greater threat to immune function? Sports Med. 36(11): 941-976.

Wernerman, J. 2008. Clinical use of glutamine supplementation. J. Nutr. 138(10): 2040S2044S.

Witard, O.C., Turner, J.E., Jackman, S.R., Tipton, K.D., Jeukendrup, A.E., Kies, A.K., and Bosch, J.A. 2012. High-intensity training reduces CD8+ T-cell redistribution in response to exercise. Med. Sci. Sports Exerc. 44(9): 1689-1697. doi:10.1249/MSS.0b013e318257d2db.

Wolach, B., Falk, B., Kodesh, E., Radnay, J., Shapiro, H., Yarom, Y., and Eliakim, A. 1998. Cellular immune response to anaerobic exercise among gymnasts and untrained girls. Pediatr. Exerc. Sci. 10(3): 227-235. doi:10.1123/pes.10.3.227.

Yaqoob, P. and Calder, P.C. 1997. Glutamine requirement of proliferating T lymphocytes. Nutrition, 13(7-8): 646-651.

Ziegler, T.R., Benfell, K., Smith, R.J., Young, L.S., Brown, E., Ferrari-Baliviera, E., Lowe, D.K., and Wilmore, D.W. 1990. Safety and metabolic effects of L-glutamine administration in humans. JPEN J Parenter. Enteral. Nutr. 14(4 Suppl.): 137S-146S.

doi:10.1177/0148607190014004201. 
Zuhl, M., Dokladny, K., Mermier, C., Schneider, S., Salgado, R., and Moseley, P. 2015. The effects of acute oral glutamine supplementation on exercise-induced gastrointestinal permeability and heat shock protein expression in peripheral blood mononuclear cells. Cell Stress Chaperones, 20(1): 85-93. doi:10.1007/s12192-014-0528-1.

Zuhl, M.N., Lanphere, K.R., Kravitz, L., Mermier, C.M., Schneider, S., Dokladny, K., and Moseley, P.L. 2014. Effects of oral glutamine supplementation on exercise-induced gastrointestinal permeability and tight junction protein expression. J. Appl. Physiol. (1985) 116(2): 183-191. doi:10.1152/japplphysiol.00646.2013. 


\section{TABLES}

Table 1 Values of different physiological parameters in respective conditions

\begin{tabular}{cccccc}
\hline & \multicolumn{2}{c}{ PLA } & & \multicolumn{2}{c}{ GLN } \\
\cline { 2 - 3 } \cline { 5 - 6 } \cline { 5 - 6 } & PRE & POST & & PRE & POST \\
\hline HR (beats/min) & $71.8 \pm 6.4$ & $187.1 \pm 7.4^{* *}$ & & $69.7 \pm 7.3$ & $184.5 \pm 12.4^{\dagger \dagger}$ \\
$\mathbf{T}_{\text {GI }}\left({ }^{\circ} \mathbf{C}\right)$ & $37.45 \pm 0.31$ & $39.35 \pm 0.41^{* *}$ & & $37.34 \pm 0.31$ & $39.27 \pm 0.43^{\dagger \dagger}$ \\
$\mathbf{T}_{\mathbf{F H}}\left({ }^{\circ} \mathbf{C}\right)$ & $37.17 \pm 0.97$ & $39.59 \pm 0.79^{* *}$ & & $37.08 \pm 0.88$ & $39.74 \pm 0.81^{\dagger \dagger}$ \\
RPE & $6 \pm 0$ & $19 \pm 1^{* *}$ & & $6 \pm 0$ & $18 \pm 2^{\dagger \dagger}$ \\
Weight (Kg) & $70.52 \pm 8.37$ & $69.38 \pm 8.30^{* *}$ & & $70.92 \pm 8.26$ & $69.93 \pm 8.25^{\dagger \dagger}$ \\
Time (min) & \multicolumn{2}{c}{$42.0 \pm 9.5$} & & \multicolumn{2}{c}{$39.6 \pm 7.8$} \\
\hline
\end{tabular}

PLA, placebo group; GLN, glutamine group; PRE, pre-exercise; Post, post-exercise; $H R$, heart rate;

$T_{G I}$, gastrointestinal temperature; $T_{F H}$, forehead temperature; $R P E$, rating of perceived exertion.

${ }^{* *} P<0.01$, compared with value at PRE in PLA.

${ }^{\dagger} P<0.01$, compared with value at PRE in GLN. 
Table 2 Values of different hematologic parameters in respective conditions

\begin{tabular}{|c|c|c|c|c|}
\hline & \multicolumn{2}{|c|}{ PLA } & \multicolumn{2}{|c|}{ GLN } \\
\hline & PRE & POST & PRE & POST \\
\hline WBC $\left(10^{\wedge} 9 / L\right)$ & $5.90 \pm 1.44$ & $7.48 \pm 1.36^{* *}$ & $6.20 \pm 1.22$ & $8.67 \pm 1.85^{\dagger \dagger}$ \\
\hline NEU $\left(10^{\wedge} 9 / L\right)$ & $3.57 \pm 1.37$ & $4.53 \pm 1.35^{* *}$ & $3.91 \pm 0.97$ & $5.57 \pm 1.69^{\dagger}$ \\
\hline NEU (\%) & $59.4 \pm 8.5$ & $58.0 \pm 8.9$ & $62.8 \pm 6.5$ & $61.6 \pm 8.8$ \\
\hline LYM $\left(10^{\wedge} 9 / \mathrm{L}\right)$ & $1.81 \pm 0.46$ & $2.45 \pm 0.76^{* *}$ & $1.79 \pm 0.49$ & $2.59 \pm 0.85^{\dagger \dagger}$ \\
\hline LYM (\%) & $31.3 \pm 7.5$ & $31.9 \pm 9.2$ & $29.3 \pm 7.5$ & $29.5 \pm 8.5$ \\
\hline $\operatorname{EOS}\left(10^{\wedge} 9 / \mathrm{L}\right)$ & $0.31 \pm 0.16$ & $0.28 \pm 0.17$ & $0.27 \pm 0.23$ & $0.25 \pm 0.17$ \\
\hline $\operatorname{EOS}(\%)$ & $5.7 \pm 3.5$ & $3.8 \pm 2.7^{* *}$ & $4.2 \pm 2.6$ & $2.7 \pm 1.4^{\dagger \dagger}$ \\
\hline BAS $\left(10^{\wedge} 9 / \mathbf{L}\right)$ & $0.03 \pm 0.02$ & $0.04 \pm 0.02$ & $0.03 \pm 0.02$ & $0.04 \pm 0.02$ \\
\hline BAS (\%) & $0.6 \pm 0.3$ & $0.5 \pm 0.2^{*}$ & $0.5 \pm 0.3$ & $0.5 \pm 0.2$ \\
\hline $\operatorname{MON}\left(10^{\wedge} 9 / \mathrm{L}\right)$ & $0.17 \pm 0.09$ & $0.18 \pm 0.09$ & $0.20 \pm 0.11$ & $0.22 \pm 0.08$ \\
\hline MON (\%) & $3.0 \pm 1.6$ & $2.4 \pm 1.3^{*}$ & $3.2 \pm 1.8$ & $2.6 \pm 1.1^{\dagger}$ \\
\hline $\operatorname{RBC}\left(10^{\wedge} 12 / L\right)$ & $5.19 \pm 0.31$ & $5.32 \pm 0.25^{* *}$ & $5.22 \pm 0.25$ & $5.32 \pm 0.27^{\dagger \dagger}$ \\
\hline HGB (g/L) & $156.54 \pm 6.80$ & $159.01 \pm 7.28^{* *}$ & $156.69 \pm 7.89$ & $159.06 \pm 9.04^{\dagger \dagger}$ \\
\hline HCT (L/L) & $0.50 \pm 0.03$ & $0.52 \pm 0.03^{* *}$ & $0.49 \pm 0.04$ & $0.51 \pm 0.04^{\dagger \dagger}$ \\
\hline $\operatorname{MCV}$ (fl) & $95.07 \pm 3.82$ & $90.43 \pm 3.93^{* *}$ & $94.86 \pm 4.34$ & $90.15 \pm 4.16^{\dagger \dagger}$ \\
\hline $\operatorname{MCHC}(g / L)$ & $315.46 \pm 10.73$ & $309.02 \pm 15.68^{*}$ & $317.15 \pm 11.99$ & $311.79 \pm 15.37$ \\
\hline MCH (pg) & $29.95 \pm 0.94$ & $28.91 \pm 1.10^{* *}$ & $30.04 \pm 0.79$ & $29.00 \pm 1.11^{\dagger \dagger}$ \\
\hline RDW-CV (\%) & $11.7 \pm 0.4$ & $11.2 \pm 0.4^{* *}$ & $11.6 \pm 0.4$ & $11.2 \pm 0.5^{\dagger \dagger}$ \\
\hline RDW-SD (fl) & $48.17 \pm 2.52$ & $45.07 \pm 2.59^{* *}$ & $47.48 \pm 3.00$ & $44.70 \pm 2.83^{\dagger \dagger}$ \\
\hline $\operatorname{PLT}\left(10^{\wedge} 9 / \mathrm{L}\right)$ & $260.46 \pm 57.02$ & $307.95 \pm 74.77^{* *}$ & $250.08 \pm 57.29$ & $316.63 \pm 72.26^{\dagger \dagger}$ \\
\hline PDW (fl) & $16.08 \pm 0.20$ & $15.55 \pm 0.35^{* *}$ & $16.02 \pm 0.17$ & $15.51 \pm 0.46^{\dagger \dagger}$ \\
\hline MPV (fl) & $10.39 \pm 0.86$ & $10.22 \pm 0.85$ & $10.30 \pm 1.20$ & $10.09 \pm 1.09^{\dagger}$ \\
\hline PCT & $0.27 \pm 0.06$ & $0.32 \pm 0.08^{* *}$ & $0.25 \pm 0.04$ & $0.33 \pm 0.07^{\dagger \dagger}$ \\
\hline
\end{tabular}

$\overline{P L A}$, placebo group; GLN, glutamine group; PRE, pre-exercise; Post, post-exercise; $W B C$, white blood cell; NEU, neutrophils; $L Y M$, lymphocytes; EOS, eosinophils; $B A S$, basophils; $M O N$, monocytes; $R B C$, red blood cell; $H G B$, hemoglobin; $H C T$, hematocrit; $M C V$, mean corpuscular 
volume; $M C H C$, mean corpuscular hemoglobin concentration; $M C H$, mean corpuscular hemoglobin; $R D W-C V$, red blood cell distribution width-variation coefficient; $R D W-S D$, red blood cell distribution width-standard deviation; $P L T$, platelet counts; $P D W$, platelet distribution width; $M P V$, mean platelet volume; $P C T$, plateletcrit.

${ }^{*} P<0.05$, compared with value at PRE in PLA.

${ }^{* *} P<0.01$, compared with value at PRE in PLA.

${ }^{\dagger} P<0.05$, compared with value at PRE in GLN.

${ }^{\dagger} P<0.01$, compared with value at PRE in GLN. 
Table 3 Changes of circulating lymphocyte subsets in respective conditions

\begin{tabular}{|c|c|c|c|c|}
\hline & \multicolumn{2}{|c|}{ PLA } & \multicolumn{2}{|c|}{ GLN } \\
\hline & PRE & POST & PRE & POST \\
\hline LYM (mol/L) & $2442.2 \pm 629.7$ & $2726.3 \pm 1049.6$ & $2084.4 \pm 534.4$ & $2815.4 \pm 1076.6$ \\
\hline $\mathrm{CD3}+(\mathrm{mol} / \mathrm{L})$ & $1848.1 \pm 531.4$ & $1907.1 \pm 690.0$ & $1549.7 \pm 481.1$ & $2019.8 \pm 822.8^{\dagger \dagger}$ \\
\hline $\mathrm{CD3}+(\%)$ & $74.8 \pm 5.6$ & $68.2 \pm 7.4^{* *}$ & $73.3 \pm 6.9$ & $69.1 \pm 4.6^{\dagger}$ \\
\hline $\mathrm{CD19}+(\mathrm{mol} / \mathrm{L})$ & $250.5 \pm 83.3$ & $206.3 \pm 103.2^{* *}$ & $241.9 \pm 103.7$ & $211.5 \pm 123.0$ \\
\hline CD19+ (\%) & $10.4 \pm 2.8$ & $7.2 \pm 2.2^{* *}$ & $11.4 \pm 3.9$ & $7.1 \pm 2.6^{\dagger \dagger}$ \\
\hline $\begin{array}{c}\mathrm{CD3}+\mathrm{CD8}+ \\
(\mathrm{mol} / \mathrm{L})\end{array}$ & $832.3 \pm 257.9$ & $894.4 \pm 338.2$ & $718.1 \pm 268.3$ & $1003.7 \pm 493.3^{\dagger}$ \\
\hline $\mathrm{CD3}+\mathrm{CD8}+(\%)$ & $33.7 \pm 5.5$ & $32.0 \pm 5.8^{*}$ & $33.8 \pm 6.5$ & $33.5 \pm 6.7$ \\
\hline $\begin{array}{c}\text { CD3+CD4+ } \\
(\mathrm{mol} / \mathrm{L})\end{array}$ & $826.8 \pm 274.4$ & $798.0 \pm 287.6$ & $727.8 \pm 228.9$ & $833.2 \pm 301.6$ \\
\hline $\mathrm{CD3}+\mathrm{CD} 4+(\%)$ & $33.6 \pm 5.4$ & $29.0 \pm 5.2^{* *}$ & $34.7 \pm 5.2$ & $29.6 \pm 6.3^{\dagger \dagger}$ \\
\hline NK (mol/L) & $261.2 \pm 85.9$ & $497.9 \pm 289.0^{* *}$ & $219.8 \pm 82.1$ & $468.5 \pm 182.0^{\dagger \dagger}$ \\
\hline NK (\%) & $11.4 \pm 4.6$ & $17.3 \pm 5.2^{* *}$ & $11.5 \pm 6.4$ & $16.5 \pm 4.3^{\dagger \dagger}$ \\
\hline CD4/CD8 & $1.04 \pm 0.29$ & $0.91 \pm 0.28^{* *}$ & $1.07 \pm 0.34$ & $0.92 \pm 0.39^{\dagger}$ \\
\hline
\end{tabular}

$\overline{P L A}$, placebo group; GLN, glutamine group; PRE, pre-exercise; Post, post-exercise; LYM, lymphocytes; $C D 3+$, total T lymphocyte; $C D 19+$, total B lymphocyte; $C D 3+C D 4+$, helper T cell; $C D 3+C D 8+$, suppressor/cytotoxic T cell; $N K$, nature killer cell (CD3-CD16+CD56+).

${ }^{*} P<0.05$, compared with value at PRE in PLA.

${ }^{* *} P<0.01$, compared with value at PRE in PLA.

${ }^{\dagger} P<0.05$, compared with value at PRE in GLN.

${ }^{\dagger \dagger} P<0.01$, compared with value at PRE in GLN. 
Table 4 Changes of serum immunoglobulins and complements in respective conditions

\begin{tabular}{cccccc}
\hline & \multicolumn{2}{c}{ PLA } & & \multicolumn{2}{c}{ GLN } \\
\cline { 2 - 3 } \cline { 5 - 6 } & PRE & POST & & PRE & POST \\
\hline $\operatorname{IgA}(\mathbf{g} / \mathbf{L})$ & $2.24 \pm 0.74$ & $2.32 \pm 0.78^{* *}$ & & $2.28 \pm 0.73$ & $2.32 \pm 0.83$ \\
$\operatorname{IgG}(\mathbf{g} / \mathbf{L})$ & $11.11 \pm 2.13$ & $11.50 \pm 2.16^{* *}$ & & $11.20 \pm 2.37$ & $11.54 \pm 2.36^{\dagger \dagger}$ \\
$\operatorname{IgM}(\mathbf{g} / \mathbf{L})$ & $1.12 \pm 0.49$ & $1.16 \pm 0.51^{*}$ & & $1.12 \pm 0.44$ & $1.14 \pm 0.46$ \\
$\mathbf{C 3}(\mathbf{g} / \mathbf{L})$ & $0.96 \pm 0.12$ & $0.99 \pm 0.12^{*}$ & & $0.94 \pm 0.10$ & $0.96 \pm 0.10$ \\
$\mathbf{C 4}(\mathbf{g} / \mathbf{L})$ & $0.22 \pm 0.08$ & $0.23 \pm 0.08^{*}$ & & $0.21 \pm 0.05$ & $0.22 \pm 0.06$ \\
\hline
\end{tabular}

$\overline{P L A}$, placebo group; GLN, glutamine group; PRE, pre-exercise; Post, post-exercise; IgA, immunoglobulin A; $\operatorname{Ig} G$, immunoglobulin $\mathrm{G}$; $\operatorname{Ig} M$, immunoglobulin $\mathrm{M}$; $C 3$, complement 3; C4, complement 4.

${ }^{*} P<0.05$, compared with value at PRE in PLA.

${ }^{* *} P<0.01$, compared with value at PRE in PLA.

${ }^{\dagger} P<0.01$, compared with value at PRE in GLN. 
Table 5 Changes of inflammatory cytokines in respective conditions

\begin{tabular}{cccccc}
\hline & \multicolumn{2}{c}{ PLA } & & \multicolumn{2}{c}{ GLN } \\
\cline { 2 - 3 } \cline { 5 - 6 } \cline { 5 - 6 } & PRE & POST & & PRE & POST \\
\hline IL-2 (pg/mL) & $31.96 \pm 3.14$ & $30.18 \pm 3.02$ & & $36.61 \pm 12.34$ & $33.58 \pm 7.59$ \\
$\mathbf{I L - 6}(\mathbf{p g} / \mathbf{m L})$ & $136.67 \pm 12.03$ & $129.53 \pm 10.66$ & & $134.44 \pm 19.13$ & $131.34 \pm 15.61$ \\
$\mathbf{T N F - \alpha}(\mathbf{p g} / \mathbf{m L})$ & $55.64 \pm 15.78$ & $53.66 \pm 16.02$ & & $55.45 \pm 19.13$ & $60.48 \pm 17.78$ \\
$\mathbf{O H}(\mathbf{U} / \mathbf{m L})$ & $710.69 \pm 30.11$ & $717.45 \pm 55.12$ & & $712.35 \pm 35.90$ & $683.71 \pm 28.59$ \\
\hline PLA, placebo group; & GLN, glutamine & group; PRE, & pre-exercise; Post, post-exercise; IL-2, \\
interleukin-2; IL-6, interleukin-6; TNF- $\alpha$, tumor necrosis factor- $\alpha ;$ OH, hydroxyl radical.
\end{tabular}




\section{FIGURES}

Fig. 1 Changes of body temperature and heart rate in respective conditions

$A$, changes of $T_{G I}$ and $T_{F H}$ from rest to physical exhaustion; $B$, change of $H R$ from rest to physical exhaustion; PLA, placebo group; GLN, glutamine group; $T_{G I}$, gastrointestinal temperature; $T_{F H}$, forehead temperature.

Fig. 2 Changes of $C D 3+, C D 3+C D 4+$, and $C D 3+C D 8+$ in respective conditions

$A$, result of $C D 3+$ measured by flow cytometry; $B$, result of $C D 3+C D 4+$ measured by flow cytometry; $C$, result of $C D 3+C D 8+$ measured by flow cytometry; PLA, placebo group; $G L N$, glutamine group; PRE, pre-exercise; Post, post-exercise; $C D 3+$, total T lymphocyte; $C D 3+C D 4+$, helper T cell; $C D 3+C D 8+$, suppressor/cytotoxic T cell. 

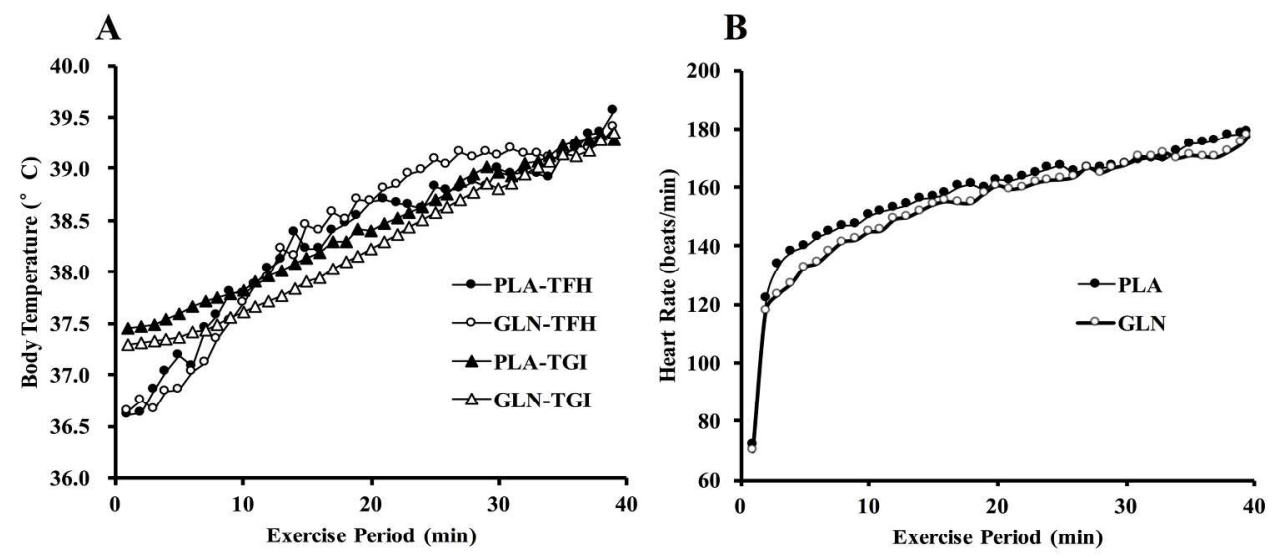

Fig. 1 Changes of body temperature and heart rate in respective conditions

A, changes of TGI and TFH from rest to physical exhaustion; $B$, change of HR from rest to physical exhaustion; PLA, placebo group; GLN, glutamine group; TGI, gastrointestinal temperature; TFH, forehead temperature.

$209 \times 148 \mathrm{~mm}(300 \times 300$ DPI $)$ 


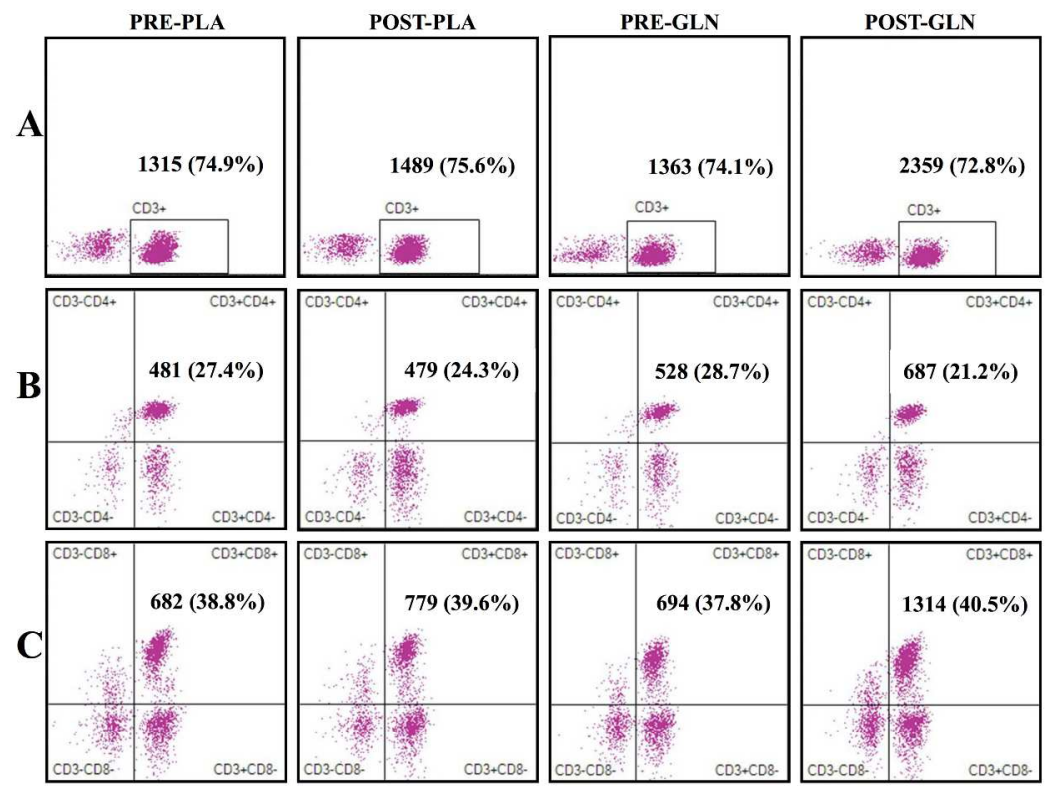

Fig. 2 Changes of $\mathrm{CD} 3+, \mathrm{CD} 3+\mathrm{CD} 4+$, and $\mathrm{CD} 3+\mathrm{CD} 8+$ in respective conditions $A$, result of $C D 3+$ measured by flow cytometry; $B$, result of CD3+CD4+ measured by flow cytometry; $C$, result of $C D 3+C D 8+$ measured by flow cytometry; PLA, placebo group; GLN, glutamine group; PRE, preexercise; Post, post-exercise; CD3+, total T lymphocyte; CD3+CD4+, helper T cell; CD3+CD8+, suppressor/cytotoxic T cell.

$297 \times 420 \mathrm{~mm}(300 \times 300 \mathrm{DPI})$ 